\title{
A Rural Next Generation Network (R-NGN) and Its Testbed
}

\author{
Armein Z. R. Langi ${ }^{1}$ \\ ${ }^{1}$ Information Technology Research Group, \\ School Department of Electrical Engineering and Informatics, and \\ Research Center on Information and Communication Technology \\ Institut Teknologi Bandung, Jalan Ganeca 10, Bandung, 40132, Indonesia \\ e-mail: langi@lss.ee.itb.ac.id
}

\begin{abstract}
Rural Next Generation Networks (R-NGN) technology allows Internet protocol (IP) based systems to be used in rural areas. This paper reports a testbed of R-NGN that uses low cost Ethernet radio links, combined with media gateways and a softswitch. The network consists of point-to-point IP Ethernet 2.4 GHz wireless link, IP switches and gateways in each community, standard copper wires and telephone sets for users. It uses low power consumption, and suitable for low density users. This combination allows low cost systems as well as multiservices (voice, data, and multimedia) for rural communications. An infrastructure has been deployed in two communities in Cipicung Girang, a village $10 \mathrm{~km}$ outside Bandung city, Indonesia. Two towers link the communities with a network of Institut Teknologi Bandung (ITB) campus. In addition, local wirelines connect community houses to the network. Currently there are four houses connected to each community node (for a total of eight house), upon which we can perform various tests and measurements.
\end{abstract}

Keywords: Rural Next Generation Network (R-NGN); Softswitch; Testbed.

\section{Introduction}

Rural communications are of strategic importance for peoples in developing countries such as Indonesia. It is important to support economic, social, as well as government needs. It is well known that increasing telephone penetration results in increasing economic growth. Unfortunately, rural communications must satisfy conflicting requirements [1]. Its business potential is not as prospective as in urban cases due to relatively poor customer segments. This low purchasing power of the users results in a low average revenue per user (ARPU) for telecom operators. Its infrastructure and equipment costs are prohibitively expensive. Furthermore, rural areas in archipelagos such as Indonesia pose difficulties in deployment and operations. As a result, the penetration of rural communication is very slow. As of today, fixed line telephone services serve only $3.5 \%$ of Indonesian populations, despite having been in service since 1882 .

Received July 6 ${ }^{\text {th }}$, 2006, Revised March 20 ${ }^{\text {th }}$, 2007, Accepted for publication March $20^{\text {th }}$, 2007. 
Various solutions have been proposed in the past, including radio, satellite, and cellular links. Such solutions are usually more expensive than its urban counterpart (more than $\$ 1000$ per user, for numbers of users as few as 16 to 32 homes for a typical village). Furthermore, such solutions usually focus on providing voice communications only. Such 19th century based communications are not only insufficient to support economic growth, but also cannot satisfy user needs in this information era.

One important consideration for new deployment is in anticipating a disruptive factor coming from next generation network (NGN) technology [2], [3], [4]. An NGN merges various networks such as public switched telephone networks (PSTN) [5], cellular, and the Internet into an interoperable Internet protocol (IP) network (see Figure 1). Such a network allows heterogeneous business of various operators, including network, service, application, and content operators to operate within an NGN. Not only this satisfies user demands but also creates significant value added revenues. This ability is especially suitable for regional autonomy based deployments and operations.

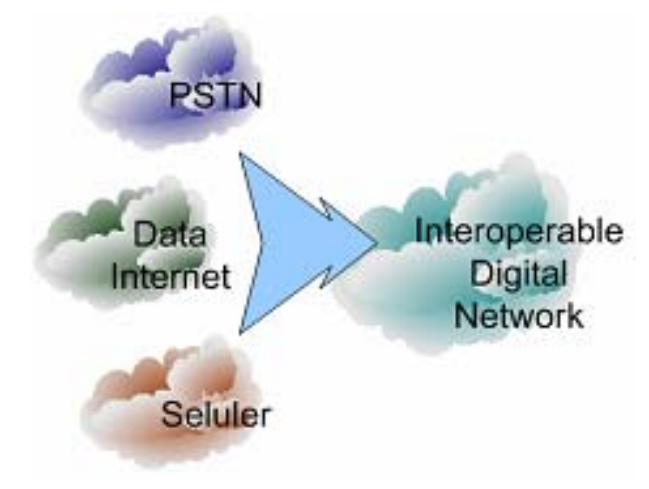

Figure 1 NGN merges PSTN, Cellular, and Internet into an interoperable network.

To satisfy user requirements as well as to anticipate the disruptive factor, we propose Rural NGN (R-NGN) to be used in rural areas. It is an NGN connecting various rural communities using point-to-point IP Ethernet wireless links. Each community has an IP router/switch and gateways to connect users' telephone sets using standard copper wires and telephone sets. The community unit uses low power consumption. The proposed network is suitable for low density users.

Despite its promising performance, R-NGN requires a testbed to test key aspects of rural communications. It is relatively new technology, thus not all of its technical aspects are well understood. Furthermore, operating a service in 
rural area requires an innovation of sustainable business models. The testbed validates the R-NGN for its infrastructure, quality of service (QoS), operation management, and user supports [2], [3].

This paper describes a design and implementation of R-NGN testbed to show the applicability of NGN technology for rural needs. The requirements of RNGN include infrastructure, operation, business models, and user supports, described in Section 2. An R-NGN is based on a concept of Community Reversed-Basestation (CRB). As described in Section 3, a CRB is a unit hosted in each community to deliver R-NGN services in a community. Section 4 shows that a typical R-NGN architecture has a Central Unit (CU) that controls all CRB in an R-NGN through dedicated point-to-point wireless links. In some cases, a CRB is too remote from the CU. Hence, an Access Unit (AU) can be used to relay signals to and from that remote CRB. Section 5 describes an implementation of R-NGN in a testbed in two communities in Cipicung Girang, a village $10 \mathrm{~km}$ outside Bandung city, Indonesia, near the campus of Institut Teknologi Bandung (ITB). Two towers have been erected to link the communities with ITB IP network. Currently there are four houses connected to each community node (for a total of eight houses). Finally, Section 6 discusses current results of the testbed implementation and concludes that R-NGN is suitable to provide NGN benefits to rural communities.

\section{Requirements of an R-NGN}

A key objective is to have a rural communication system that (1) is suitable for good communication services in tropical environment, (2) allows affordable and maintainable communication services to be deployed, (3) supports a sustaining business model, and (4) is best in providing most of benefits to community users. A successful rural telecommunication deployment must satisfy generic requirements, namely (1) an infrastructure, (2) a set of services, (3) a set of business objectives, and (4) well targeted users, shown in Figure. 2.

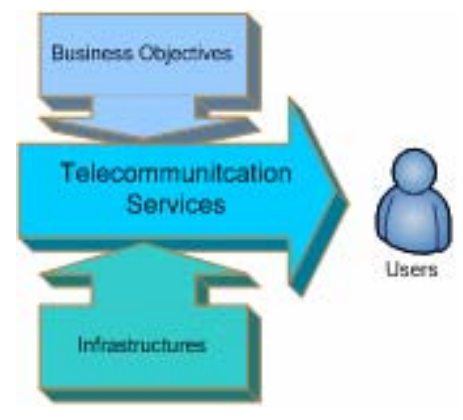

Figure 2 Generic requirements of rural telecommunications. 
The requirements are:

1. The infrastructure (consisting of core network, access network, and user network) must be reliable (able to sustain 24 hours a day operation), easy to maintain in rural areas, and affordable (preferably less than $\$ 1000$ per user).

2. The operation must provide high quality services that are consistent, useful, and affordable for rural users. The system should be able to deliver multiservices, including telephone, facsimile, messaging, email, and Internet. In additions, the system can also deliver video conferences and future multimedia applications without major infrastructure modifications (see Figure 3).

3. Business models must allow sustainability of operating the network as well as growth of services. The business also involves community small businesses.

4. Users are well targeted, maximizing usages of the network for economic, social, and public service activities.
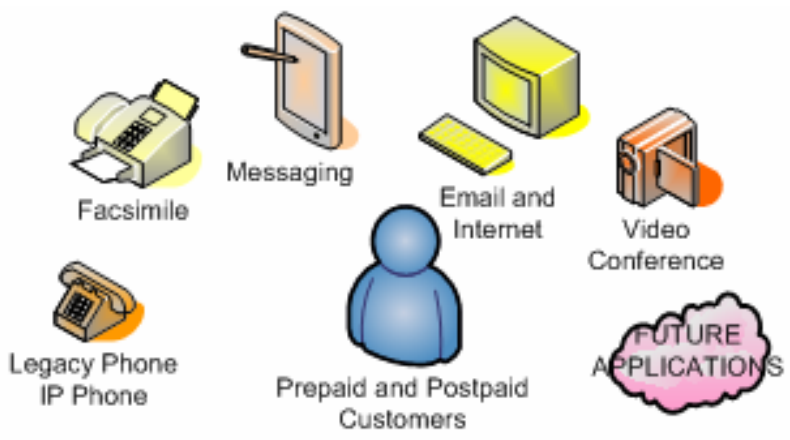

Figure 3 Applications include voice, fax, data, and future applications.

\section{Community Reversed-Basestation (CRB)}

As mentioned earlier, our proposed R-NGN relies heavily on a unit (or component) called Community Reversed Basestation, CRB, used in each rural community. Shown in Figure 4, the basestation is a node serving user terminals, as well as a relaying node to connect to the next CRB. A cellular basestation usually uses wireless links to connect to user terminals and often uses wired links to connect to a core network. In contrast, our CRB is the opposite. It uses copper wires and low costs analog telephone sets for users. In addition, it uses point to point IP Ethernet wireless (radio) links as the core network. Hence, it is called reversed basestation. 


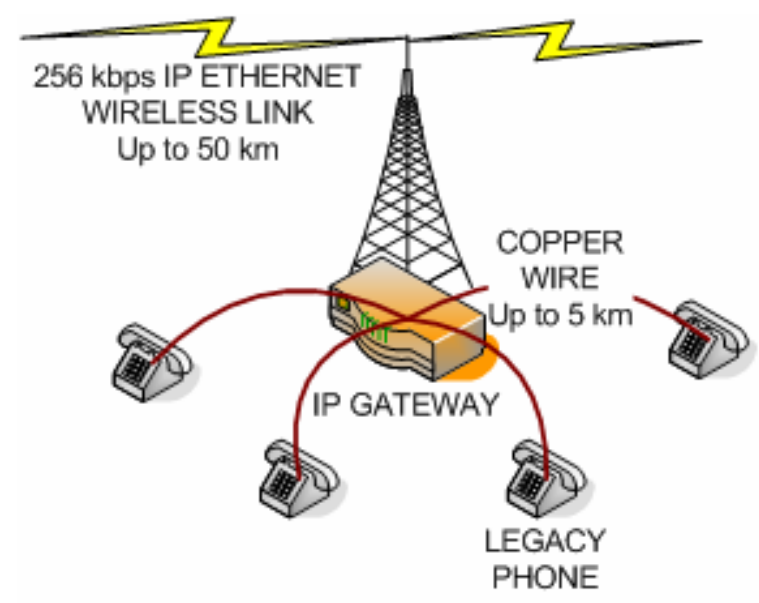

Figure 4 Community Reversed Basestation.

A CRB can have an option of radio links of $64 \mathrm{kbps}$ to $256 \mathrm{kbps}$. It is expected that such a link can operate at radio wave bands (frequencies below gigahertz), enabling long distances up to $50 \mathrm{~km}$. The link provides IP traffics containing voice and data over IP. A switch either relays the voice information to the next CRB or sends it to an access gateway. An access gateway converts the IP traffics into voice signals suitable for analog terminal sets.

Key features of a CRB are low power consumption, compact in size, and easy to deploy and maintain in rural areas. The power consumption is less than 10 watt per CRB with four user terminals. This allows a use of solar panel power supply system to back up the operation power requirement. The size of the unit is compact enough to be deployed. A local technician, after a short training, should be able to deploy and maintain a CRB.

\section{A Typical Architecture of R-NGN Infrastructure Using CRB}

\subsection{Generic Architecture}

A generic use of a CRB in an R-NGN is shown in Figure 5. The assumption is that the R-NGN is deployed in an area with hundreds of communities, and it coexists with a PSTN system. The R-NGN consists of a Central Unit (CU), several Access Units (AU), and many Community Units (CoU). In essence, a $\mathrm{CoU}$ is a realization of a CRB. An Access Link (AL) connects a CU and an AU through a high speed (7-8 Mbps) Ethernet radio link. A Community Link (CL) connects an AU to a CoU through a low bit rate (115-256 kbps) Ethernet radio link. A Central Link connects a PSTN central office (called STO) to a CU through one or more E1 links (nE1). 


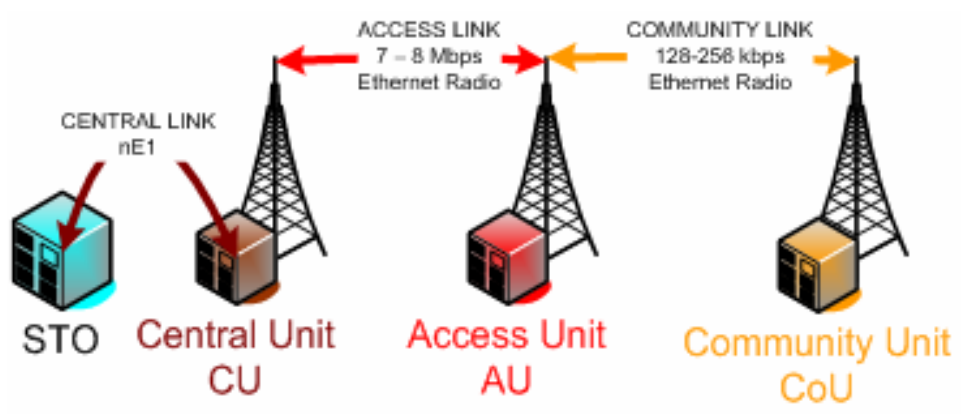

Figure 5 A generic R-NGN using CRB.

An implementation of the R-NGN to a typical rural area is shown in Figure. 6. Each R-NGN has one CU, acting as its host and is located at the nearest PSTN central office. The CU controls and distributes the traffics to several AU located preferably in towns. From AU, the traffic then travels to each community in a star configuration. Some CoU may be too remote from an AU. In this case, the nearest $\mathrm{CoU}$ acts as a relay to the remote $\mathrm{CoU}$.

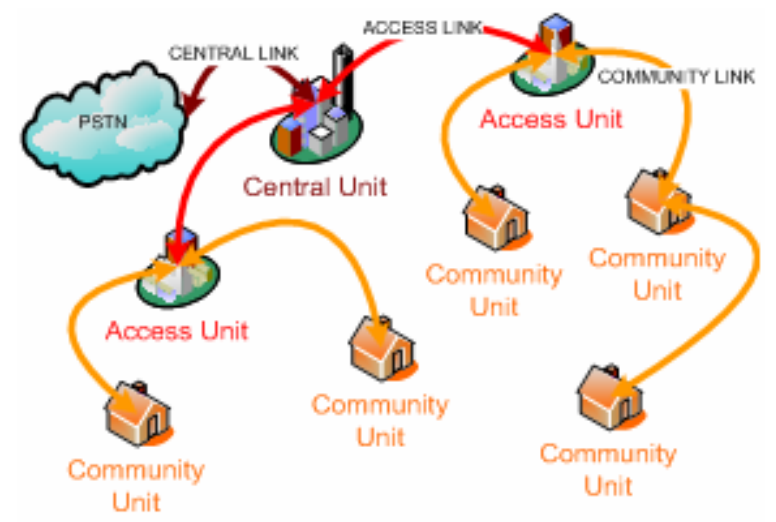

Figure 6 A typical R-NGN implemented in an area.

\subsection{A Central Unit (CU) Configuration}

A CU is a controller of the network. In addition, it is a gateway to the PSTN. As shown in Figure 7, the CU is a local area network (LAN) with a switch, having a soft switch, a central server, a PSTN/central gateway, and access link ports. A soft switch registers user terminals, setting up calls, terminating calls, and recording call durations. The central server provides authentication, authorization, and accounting (AAA) functions. The central gateway links the voice traffics from the R-NGN to PSTN. Finally, the access link ports provide Ethernet links to Access Link modules to allow Ethernet bridging to all AU. 


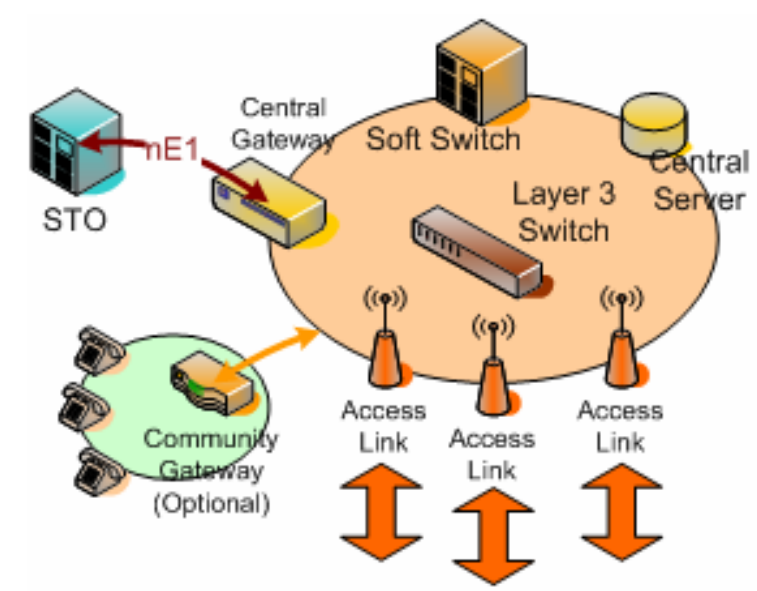

Figure 7 Logical configuration of a CU.

In some cases of new areas, it is possible that at the location of the CU there is no local service available. An optional Community Gateway provides a solution for the telephone service needs. A Community Gateway converts IP traffics into individual analog telephone sets.

\subsection{An Access Unit (AU) Configuration}

An AU is an access node that serves several clusters of communities. As shown in Figure 8, an AU is a LAN (with a switch) connecting AL ports and CL ports. An AL connects CU and AU in a much higher bit rates than those of CL.

In some cases, the town hosting an AU does not have telephone service. As before, our solution is to offer an optional Community Gateway to direct voice traffics to user telephone sets.

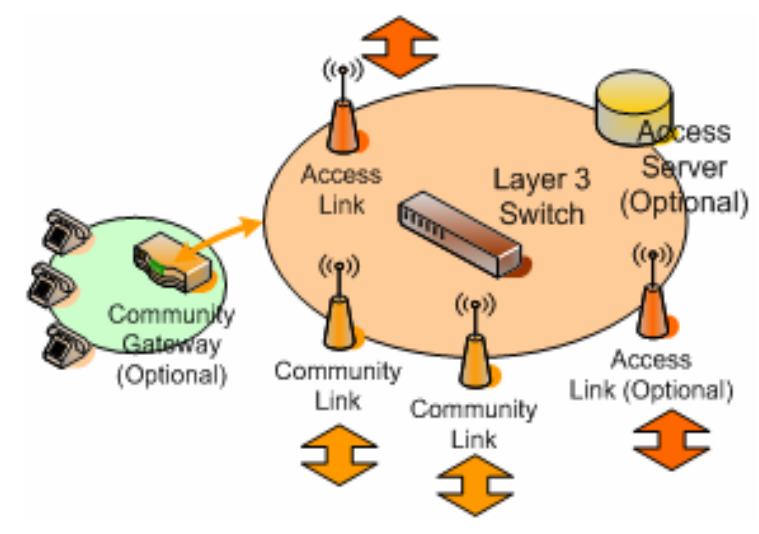

Figure 8 Logical configuration of AU. 
The communities served by an AU may want to have an optional server. The server, for example, can host various local contents and messages. The use of an IP network allows an AU to host the server.

\subsection{A Community Unit (CoU) Configuration}

A CoU is also a LAN, providing final access node to user's telephone sets, shown in Figure 9. It has an AL port to an AU. Its community gateway serves users' phone sets. A solar panel and generator set back the system power up.

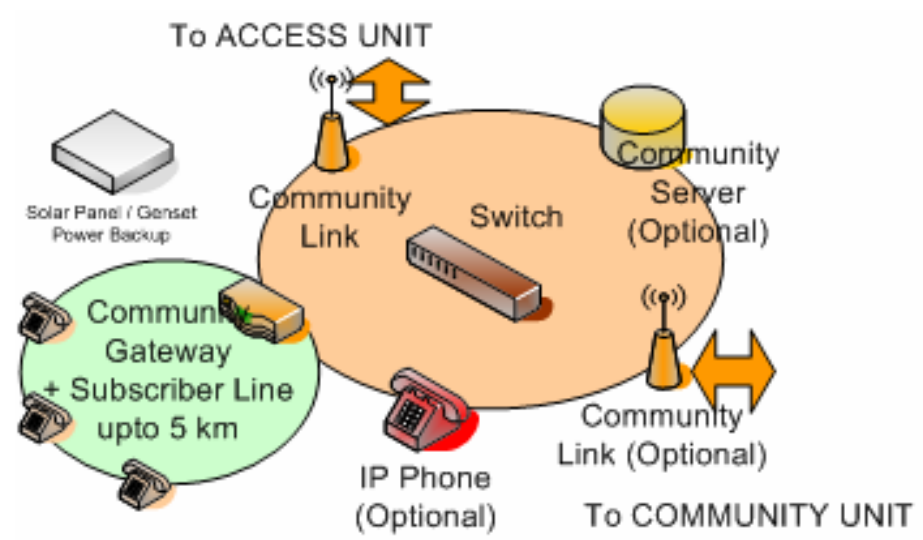

Figure 9 Logical configuration of CoU.

Optionally, CoU can also use new IP phones, computer soft phones, as well as other IP based equipment. Hence the CoU allows new generation services to use the R-NGN without major modification in the deployed network. Some communities can also maintain optional Community Servers for various local needs. A CoU can also serve as a relay for another remote CoU.

\subsection{R-NGN Capacity}

The architecture is an IP network. Hence it is important to forecast its traffic performance. Figure 10 shows a simple logical view of the network. It is a hierarchy of switches and terminals of voice over IP.

It should be noted that well known traffic capacity concept is available for circuit switch cases. Specifically, the traffic capacity is measured by hundreds of call seconds, CCS or Erlang. Three minutes of call generates a traffic of 1.8 CCS. One Erlang is the amount of calling that fully occupies a voice channel for a time interval. One hour measurement of one hour calling results in one Erlang or, equally, 36 CCS. 


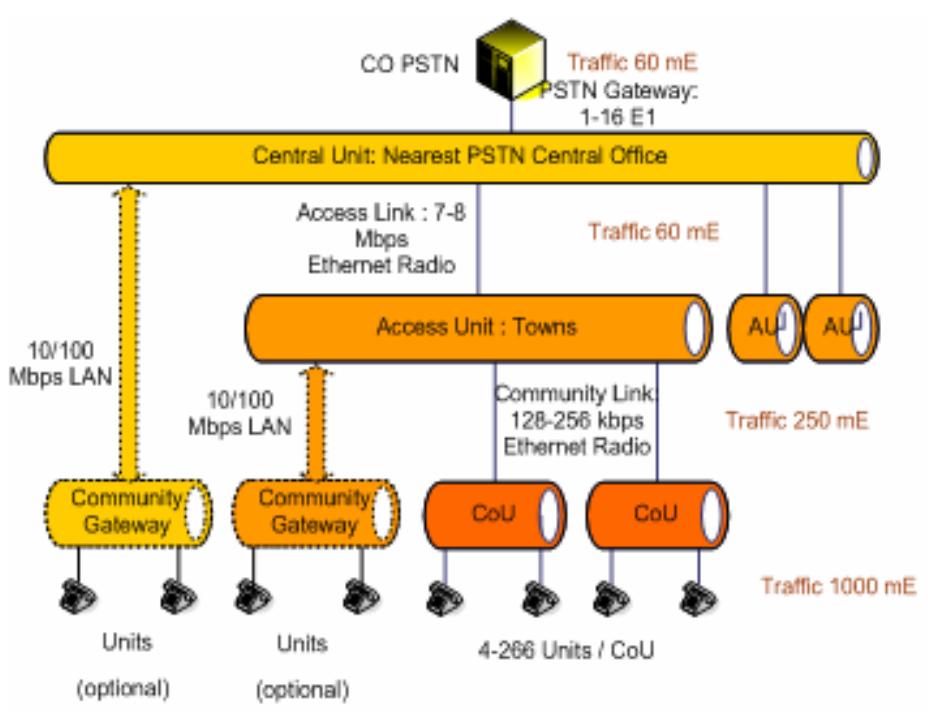

Figure 10 Logical structure for traffic analysis.

If the traffic exceeds capacity, then any subsequent call will be blocked. Probability of a call being blocked during busy time increases if the number of channels is reduced. A grade of service is measured by this probability. P01 is a grade of service with blocking probability of $1 \%$, in which 1 call is blocked for every 100 calls.

Although voice over IP is not circuit switched, it is useful to obtain comparable measures. In VoIP system, a call is not usually blocked. Instead overtraffic will result congestions, queuing, delays, jitters, buffer overflow, and packet losses [6]. However, ideas form circuit switch still can provide useful insights on RNGN performance, as follows.

To measure the R-NGN capacity, we consider four scenarios of calls according to the hierarchy:

1. Call inside community

2. Call inter communities

3. Call intra R-NGN

4. Call outside community (through PSTN gateway)

In all cases we assume to use G.729 voice codec, 10 ms frame time, and 10 bytes per frame. Furthermore, we assume 3 frames per packet, 48 bytes packet overhead, $40 \%$ activity, and $35 \%$ burstiness of voice. Finally, we want the equivalent blocking probability to be no more than $1 \%$. 
Case 1: Call inside community. The limiting factor is $100 \mathrm{Mbps}$ switch. Using the above assumptions, such a capacity can handle traffic load of 7895 Erlang, which is very abundance, given the number of users in a community may be less than 100 .

Case 2: Call inter communities. The limiting factor is now 256 kbps link. This limitation results in load capacity of 12 Erlang.

Case 3: Call intra R-NGN. There are two limiting factors: the 256 kbps community link and 8 mbps access link, which is capable of handling 31 community links. If the access link handles 31 or fewer communities, the 256 kbps link becomes the limiting factor to achieve of 12 Erlang. Otherwise, the capacity is lower.

Case 4: Call outside community. Here, the limiting factor is mostly the gateway capacity. At P01, one E1 results in 20 Erlang.

From the above analysis, we can conclude that the limitation of number of users is determined more by the community link inside R-NGN link and gateway link to PSTN.

\section{An R-NGN Testbed}

\subsection{Survey of Target Area for Deployment}

We have selected two communities (RT 03 and RT 05) located in Punclut area about ten km northern of Bandung City, Indonesia, in a village called Cipicung Girang (Figure 11). Cipicung Girang is part of an administrative area (called Kecamatan) Cidadap of 50 thousand populations. Cipicung Girang has approximately 240 families, without telephone lines.

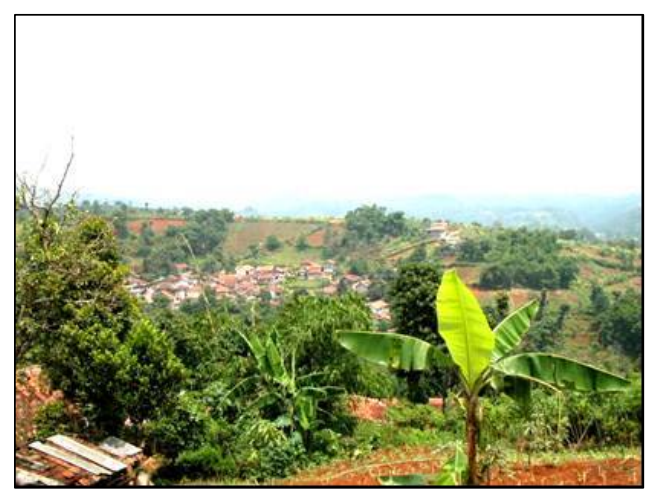

Figure 11 View of a Community in Cipicung Girang Village. 
We plan to connect both communities with ITB network, thus we can perform various measurements and tests easily. We have secured two locations, one for each community to host the equipment (Figure 12).

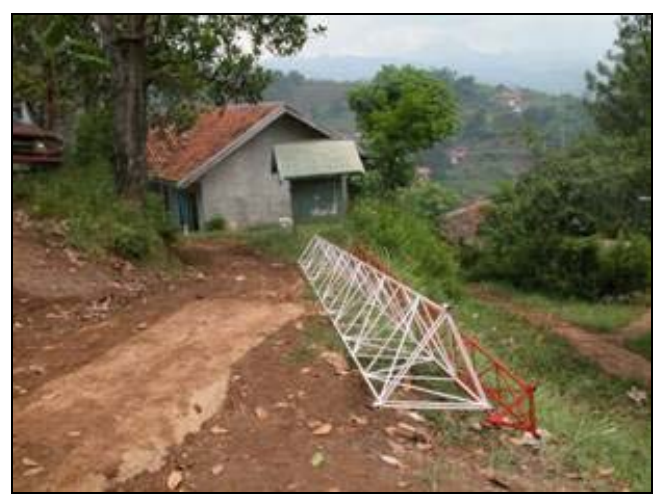

Figure 12 Target area in Cipicung Girang for deployment of our infrastructure.

\subsection{Design, Implement Network, and Test}

We have set a link between ITB and two communities in Cipicung Girang (see Figure 13). For our trial, we focus on providing community unit and community link using $24 \mathrm{dBi}$ grid parabolic antenna and outdoor wireless bridge operating at $2.4 \mathrm{GHz}$. Two self sustained towers installed at each community have a height of 20 and 10 meters, respectively (see Figures 14 and 15). This approach is quite similar to [7].

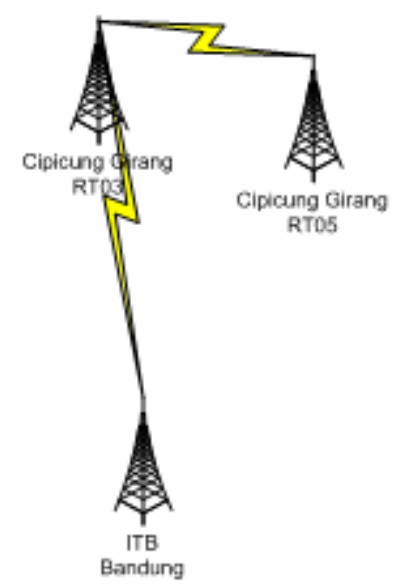

Figure 13 A network is set between ITB Bandung and two communities in Cipicung Girang. 
From each tower, there is a LSN switch that provides traffics to customer units. There are two types of units: IP phone and legacy phone. We use UTP connections for IP phones and two wire cables for legacy phone. We have eight phones deployed at this stage, four for each community.
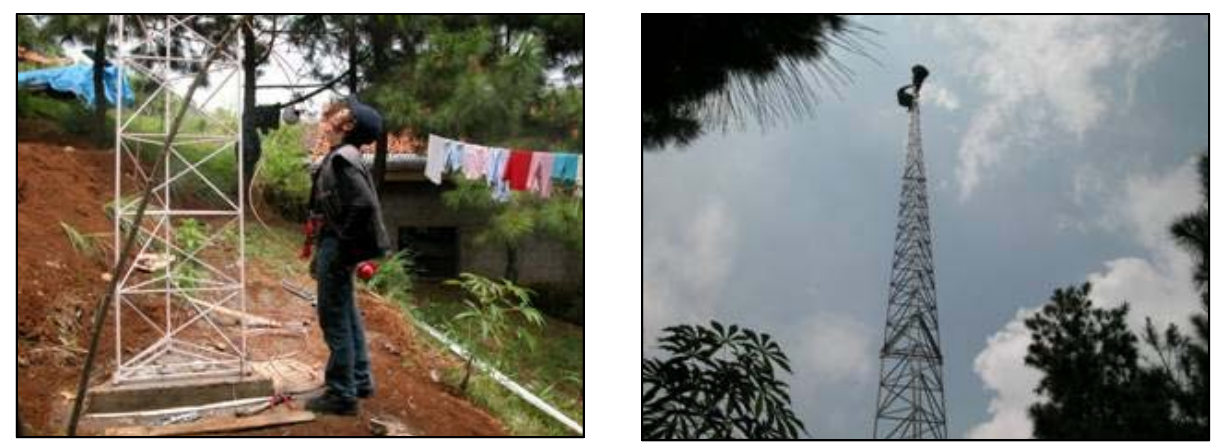

Figure 14 A tower has been erected at each location, and a technician is installing the Ethernet bridge.
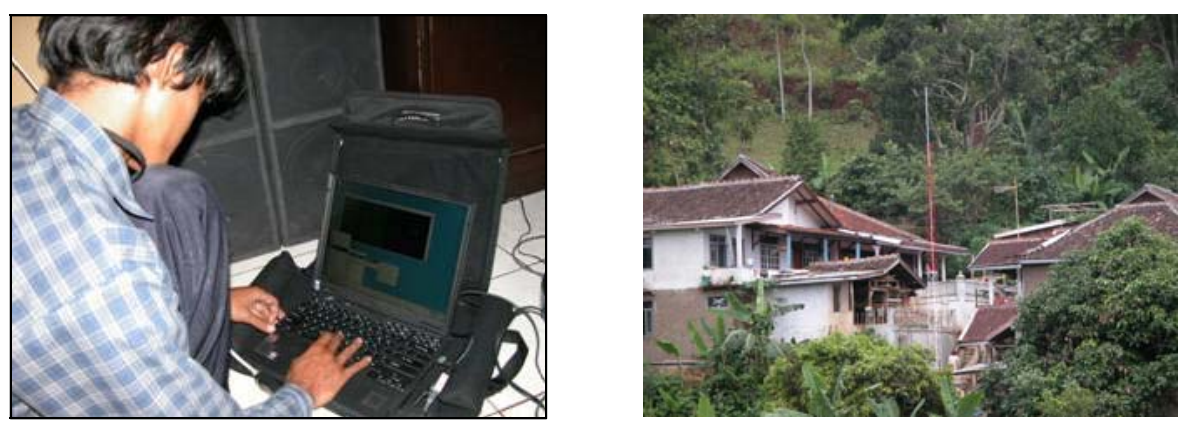

Figure 15 A technician is testing the link, and a view of the second tower.

\subsection{Services}

The testbed can provide several NGN services such as:

1. Telephone services (local and international calls), using standard telephone sets as well as IP phone sets.

2. Facsimile and messaging (SMS)

3. Internet access

4. Video phone using TV sets.

However, at this time, not all services are offered due to the need to introduce operator body. Such operation requires interconnection and legal support from 
licensed telecommunication operator. Instead we currently provide local calls within the community as well as Internet access to ITB digital library. We also provide limited call access to PSTN (for local and international calls, see Figure 16) through a gateway with a simple billing system.
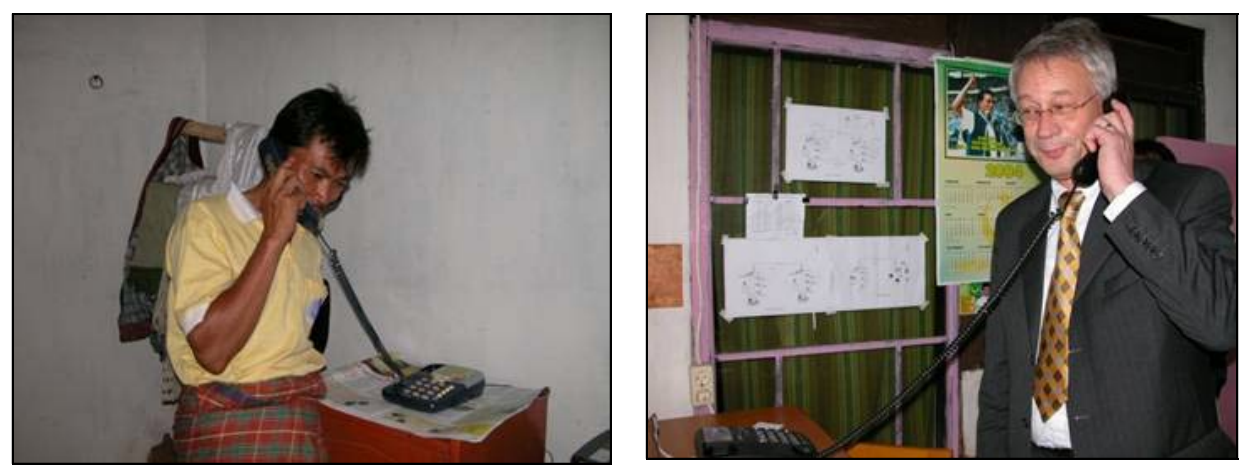

Figure 16 Tests for local and international calls.

\subsection{Community Socializing}

The success of this project also depends heavily on supports from the villagers. The research team must be in contact with the villagers to explain the importance of the project for their community. We have conducted a village meeting to socialize the project. The people expressed hopes that the project can be completed as soon as possible (Figure 17).
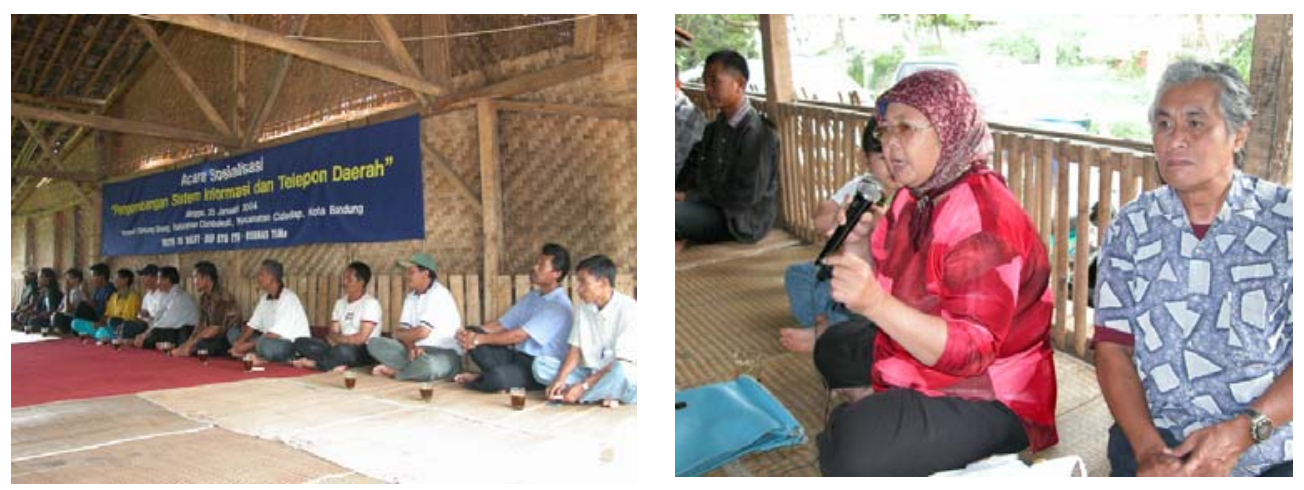

Figure 17 Meeting with villagers, in which they expressed their supports for the project. 


\section{Discussions and Conclusions}

The R-NGN is capable of providing rural communication using advanced technology. It can cover needs of various rural areas with configurations of modular CU, AU, and CoU. As shown in Table 1, R-NGN compares favorably with other alternatives, namely Satellite, Cellular: PSTN, and wireless LAN (WLAN) solution. The advantages of R-NGN are:

1. R-NGN is capable of providing multiservices similar to Cellular technology. In contras, satellite and PSTN technology is limited to voice services.

2. R-NGN technology is based on IP technology similar to WLAN, while satellite and cellular solution uses old circuit switched technology

3. Usage cost for users of R-NGN is comparable to PSTN which is lower than that of Satellite and Cellular.

4. Deployment cost for rural areas is comparable to WLAN and lower than that of satellite and cellular solution.

5. R-NGN uses low cost PSTN terminal sets, which is negligible compared to sets for cellular and satellite solutions.

6. R-NGN is basically fixed-line, thus provides equal user experience as in PSTN. Thus it is more suitable for universal service obligation (USO) program.

7. As an NGN, R-NGN offers plenty applications beyond voice communications.

8. R-NGN can be developed locally by domestic industry, thus providing more sustained support and triggering local economy.

Table 1 Comparison of various network options.

\begin{tabular}{|c|c|c|c|c|c|}
\hline Aspects & R-NGN & Satellite & Cellular & PSTN & WLAN \\
\hline Services & $\begin{array}{c}\text { Telephone, Fax, } \\
\text { Data, Internet, } \\
\text { SMS }\end{array}$ & Telephone, Data & $\begin{array}{l}\text { Telephone, Data, } \\
\text { SMS, Internet }\end{array}$ & $\begin{array}{l}\text { Telephone, } \\
\text { Fax }\end{array}$ & $\begin{array}{l}\text { Data, Messaging } \\
\text { Internet }\end{array}$ \\
\hline Technology & 3G / IP & 1G/TDMA & $\begin{array}{c}2 \mathrm{G} / 2.5 \mathrm{G} \\
(\mathrm{GSM} / \mathrm{CDMA})\end{array}$ & $1 G$ & $3 G$ \\
\hline User Tariff & $\begin{array}{c}\text { Low } \\
\text { (PSTN/VoIP) }\end{array}$ & High & High & Low & Very Low \\
\hline $\begin{array}{c}\text { Cost for Rural } \\
\text { Deployment }\end{array}$ & Low & High & High & High & Low \\
\hline $\begin{array}{l}\text { Cost For } \\
\text { Customer } \\
\text { Terminal }\end{array}$ & $\begin{array}{l}\text { Low/Easy to buy } \\
\text { in rural area }\end{array}$ & $\begin{array}{l}\text { Expensive/ } \\
\text { Difficult to buy } \\
\text { in rural area }\end{array}$ & $\begin{array}{l}\text { Expensive/Not } \\
\text { easy to buy di } \\
\text { rural areas }\end{array}$ & $\begin{array}{c}\text { Low/Easy to } \\
\text { buy in rural } \\
\text { area }\end{array}$ & $\begin{array}{l}\text { Expensive/ } \\
\text { Difficult to buy } \\
\text { in rural area }\end{array}$ \\
\hline Fixed Line & Yes & No & No & Yes & No \\
\hline
\end{tabular}




\begin{tabular}{cccccc}
\hline Aspects & R-NGN & Satellite & Cellular & PSTN & WLAN \\
\hline $\begin{array}{l}\text { Next Generation } \\
\text { Application }\end{array}$ & Plenty & Limited & Many & No & Plenty \\
$\begin{array}{c}\text { Local Industry } \\
\text { Yes }\end{array}$ & Very Limited & Very Limited & Yes & Very Limited \\
\hline
\end{tabular}

We have established the infrastructure to further study our proposed R-NGN. The infrastructure consists of a Community Link from ITB to Cipicung Girang RT03 and RT05. The link uses $2.4 \mathrm{GHz}$ wireless link. This R-NGN should be used in various rural areas in many parts of Indonesia.

\section{Acknowledgments}

The research is contributed by Yoanes Bandung, Herry Sitepu, Mervin Hutabarat, Adit Kurniawan, Nana Rahmana, and Andrian Venema. The Rural Next Generation Network (R-NGN) concept uses ideas of our proposal to Kabupaten Bandung by DSP RTG team ITB [8] and JETELPEDES by Rachma Sugeng [9]. The R-NGN is used in KITNas's USONET [1]. This research is partially funded by IRCTR TU Delft and RUSNAS TIMe.

\section{References}

[1] KITNas, Proposal dan deployment plan: Membangun system komunikasi masyarakat untuk program USO di Indonesia, Konsorsium Industri Telekomunikasi Nasional, ITB, 2003.

[2] Schollmeier, G. \& Winkler, C., Providing sustainable QoS in Next Generation Networks, IEEE Communication Magazine, pp. 102-107, June 2004.

[3] Maniatis , S. I., Nikolouzou, E. G. \& Venieris, I. S., End-to-End QoS specification issues in the converged all-IP wired and wireless environment, IEEE Communication Magazine, June 2004, pp. 80-86.

[4] Knightson, K., Morita, N. \& Towle, T., NGN Architecture: Generic Principles, Functional Architecture, and Implementation, IEEE Communication Magazine, Oct 2005, pp46-56.

[5] Michael Noll, A., Introduction to Telephones \& Telephone Systems, Second Edition, Artech House, 1991.

[6] Davidson, Jonathan \& Peters, James, Voice over IP Fundamentals, Cisco Systems, Cisco Press, 2000.

[7] Rahman, B. \& Chebrolu, K., Experiences in using WiFi for rural Internet in India, IEEE Communication Magazine, pp.104-110, Jan 2007.

[8] Langi, Armein Z. R., Proposal dan deployment plan, Sistem Komunikasi Daerah Kabupaten Bandung, Clarisense Digital Media, November 2002.

[9] Proyono, R. S., Jaringan Telekomunikasi Pedesaan Terpadu (Jatelpedes), Trans Komunikasi Data (TKD), Agustus 2003. 